\title{
MELISO DE SAMOS: LA CORRECCIÓN DE LA ONTOLOGÍA \\ PARMENÍDEA Y SUS INEVITABLES CONSECUENCIAS ESCÉPTICAS.
}

Ramón Román Alcalá Facultad de Filosofía. Córdoba

Formular y justificar algunas proposiciones sobre Meliso lleva inevitablemente al encuentro con Parménides. En este artículo me propongo analizar algunas dificultades de la ontología parmenídea que obligaron al de Samos a revisarla. Empezaré por considerar algunos conceptos tradicionales, cuya incuestionabilidad vacila, a veces, ante un examen severo. Como observa Aubenque ${ }^{1}$, sólo una cierta tradición que comienza en Parménides justifica la idea de que el ser debe ser el tema privilegiado de toda teorización filosófica. Pero es falso creer que históricamente esta figura de pensamiento ha sido dominante. Solamente, Parménides primero

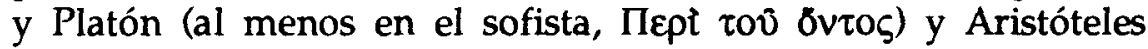
después, hacen del ser el objeto principal de su filosofía. Es evidente, que esta línea Parménides-Platón-Aristóteles sobresale con el nombre de "metafísica" en la historia de la filosofía, pero también es cierto que queda bastante aislada en el pensamiento griego, donde nace. La originalidad de Parménides al elegir el ser como nombre clave de la parte más decisiva de su poema está fuera de duda. Aunque, es curioso que en la evolución posterior el sujeto original, el soporte de todos los predicados del $\tau \partial$ ع $\delta \mathrm{V}$ cae en el olvido y son sólo los predicados del ser los que continúan como problema.

\footnotetext{
1 AUBENQUE, P., "Syntaxe et sémantique de l'être dans le poème de Parménide» en Études sur Parménide, 2 tomos (tomo I, Le poème de Parménide y tomo II, Problèmes d'interprétation), Paris, 1987, tomo II, pp. 102-134, principalmente, pp. 103-105.
}

Éndoxa: Series Filosóficas, $n^{\circ}$ 3, 1994, UNED, Madrid:

Ramón Román Alcalá: Meliso de Samos: La corrección de la ontología parmenídea.. pp.179-193. 
Lo más curioso de este caso es que si bien la tradición que se reclama como deudora de Parménides ha asumido, interiorizado su propuesta principal, también es cierto que la ha olvidado. Aristóteles y la tradición doxográfica la resume asi: «Considerando, en efecto, que, fuera del ser, el no-ser no es nada, piensa (Parménides) que necesariamente el ser es uno y que no es ninguna otra cosa» ${ }^{2}$. $Y$ también Teofrasto, citado por Simplicio, aporta el siguiente esquema: «Lo que está fuera del ser es el no-ser; pero el no-ser no es nada; pues el ser es uno». De la inexistencia de lo que no es, se concluye la soledad del

ser, de ahí a su unicidad, después a su unidad y por fin a su inmovilidad. El inconveniente de esta presentación tradicional es que hace recaer la innovación parmenídea sobre la determinación de los predicados del ser y no sobre la elección del ser como sujeto: la tesis parmenídea corre el riesgo de aparecer como una hipótesis más entre otras, la que afirma la unidad del ser, por oposición a otras que afirmarían su pluralidad o su divisibilidad.

Esta presentación tradicional comporta un doble defecto:

1/ Privilegia sin evidencia suficiente lo que no era en Parménides más que un corolario entre otros de una tesis original: el predicado de la unidad no aparece más que en el v. 6 del fr. VIII, después de haber sido nombrado la no generación, la incorruptibilidad, la homogeneidad, el infinito.

2/ Esta presentación sin duda fundada sobre la convicción de Aristóteles y de sus comentadores de que la filosofía no puede hablar de otra cosa que de "lo que es», desconocía la originalidad de Parménides que es hacer por primera vez de o del "ser" el tema de la especulación.

\section{I}

Hasta aquí razonablemente podemos estar de acuerdo, pero la cuestión es: ¿por qué la tradición entiende así a Parménides? ¿Qué hay en el Poema que genere esta confusión? La clave a estas

2 ARISTÓTELES, Metaf., A 5, $986 \mathrm{~b} 29$.

3 SIMPLICIO, Phys., 115, 11: DK 28 A 28. 
preguntas creo que puede encontrarse en la reconstrucción que Meliso se ve obligado a hacer de la ontología parmenídea.

La consideración de Meliso ${ }^{4}$ como discípulo de Parménides por algunos doxógrafos posteriores posiblemente esté basada más en la similitud de las doctrinas que en la relación directa que entre ellos pudo darse. No podemos ni siquiera saber si ambos filósofos llegaron a encontrarse alguna vez, o de dónde le llegó a Meliso la influencia parmenídea ${ }^{5}$ : si bien tenemos pocas noticias de la vida de Meliso, poseemos un texto muy claro en donde, explícitamente, Diógenes Laercio lo hace discípulo de Parménides; aunque también es cierto que nos pone en la pista de una relación con Heráclito poco justificada: "Este, Meliso de Samos, hijo de Itageno, oyó a Parménides, aunque también entró en conversación con Heráclito ${ }^{6}$. El mérito de Meliso ${ }^{7}$, en cualquier caso, es el de ser el

4 Para la situación cronológica de Meliso véase el capítulo que le dedica DIÓGENES LAERCIO (D.L.) en Las Vidas IX, 24 (DK 30 A 1). Este autor citando a Apolodono coloca el florecimiento de Meliso en la Olimpíada 84. Nos da algunas noticias de su vida, como que fue nombrado sobre el 441 ó $\mathbf{4 4 0}$ almirante de la flota de Samos. Se dice que fue un gran estratega y luchó contra Pericles. El resultado le fue favorable, pues aprovechando un error de Pericles batió a la flota de los atenienses (siempre resulta curioso que un general conocido por su rapidez de acción como fue Meliso creyera que el movimiento era imposible). Al parecer fue un hombre dedicado íntegramente a la política y ocupado en los asuntos civiles, por lo que fue estimado y reconocido por sus conciudadanos. Cfr., ARISTÓTELES, Metaf., A, 5, 986 b 18: DK 21 A 30; ARISTOTELES, De caelo, G, 1, 298 b 14: DK 28 A 25; ARISTÓTELES, Física, G, 6, 207 a 9: DK 28 A 25; PLATÓN, Teeteto, 181 a: SEXTO EMPIRICO, Contra los Matemáticos (SEXTO, M.)., X, 46: DK 28 A 26; AECIO, I, 24, 1: DK 28 A 29; AECIO, II, 1, 2: DK 28 A 36.

5 Las referencias tanto de D.L., IX, 24: DK 30 A 1; de PLATÓN, Teeteto, 180 e: vid., UNTERSTEINER Melisso, Testimonianze e Frammenti, p. 332 y Teeteto, 183 e: Op. cit. p. 338; de ARISTÓTELES, Fis., 186 a 6: DK 30 A 7: Fis., 207 A 9: DK A 11; de ISOCRATES, Antid., 15, 268: Op. cit., p. 332; de FILODEMO, Retor., III, 7: DK 30 A 14 y de SEXTO, M., X, 46: DK 28 A 26 , muestran el estrecho vínculo que ya en la misma antigüedad se estableció entre Parménides y Meliso, en donde éste último jugó un papel de riguroso sistematizador del pensamiento eleático, que intenta elevar a sus máximas consecuencias los postulados parmenídeos sobre el pensamiento racional y trata de superar las posibles deficiencias. De ser esto así, podemos conjeturar que existió una gran fluidez en la circulación de ideas en esta época, pues tuvo que ocurrir que las teorías de Parménides, superando las fronteras de Elea, llegasen hasta el corazón del Egeo, a la isla de Samos, de cultura Jonia.

6 D.L., IX, 24: DK 30 A 1. 
último elaborador positivo de la concepción eleática del ser. $\mathrm{Al}$ margen de la cronología Meliso es el ideal seguidor de las doctrinas de Parménides, mejor que Zenón, cuyo intento de refutar dialécticamente a los oponentes de Parménides ${ }^{8}$, llevó a la lógica eléata al colapso. En el contexto de esta diversidad de influencias intelectuales se entiende la noticia de Aecio que enfoca nuestro análisis: «Fue adepto de Parménides, pero no conservó inalteradas las enseñanzas recibidas". En ese no conservar las enseñanzas se reconoce, como veremos, una de las fracturas más interesantes de la filosofía.

Ya desde la antigüedad pareció que Meliso se apartó de las doctrinas de Parménides, al deducir de los textos de su maestro que $e l$ ser era infinito. Mientras en el fr. 1 se demuestra la eternidad del ser, en el fr. 2 (que va integrado con los fragmentos 3,4 y 4a) es demostrada la infinitud del ser mismo:

«Puesto que no es nacido, es y siempre era y siempre será, y no ha tenido principio ni fin, sino que es infinito $\left(\& \pi \varepsilon 1 p o v^{10}\right)$. Si

7 Las fuentes para acceder al pensamiento y a las doctrinas de Meliso se encuentran en Aristóteles y en Simplicio (el cual transmite diez fragmentos supuestamente literales de Meliso), además del ya famoso y controvertido tratado anónimo "De Meliso, Jenófanes y Gorgias" (siempre que lo citemos utilizaremos la abreviatura M.J.G.).

8 Zenón fue un entusiasta discipulo de Parménides que concentró toda su capacidad intelectual, tal como nos dice Platón, en una sola tarea: la defensa del lógos de Parménides, cfr. PLATON, Parménides, 128 a.

AECIO, I, 3, 14: DK 30 A 9.

${ }^{10} \mathrm{Cfr}$. DK 30 B 2, 3, 4 y 4a. La introducción del infinito como carácter esencial del ser, constituye la reforma más sublime aportada por Meliso a la doctrina parmenidea. Según Aristóteles, Meliso comete un error considerable en el razonamiento sobre el infinito. Partiendo del poema de Parménides, dice Aristóteles que un correcto procedimiento nos llevaría a deducir de la condición, la consecuencia; pero de la consecuencia no se puede deducir la condición: la observación aristotélica señala que $A \rightarrow B$ es equivalente $\neg B \rightarrow \neg A$ (ley de contraposición del condicional), pero no a $\neg \mathrm{A} \rightarrow \neg \mathrm{B}$ como hace Meliso. Aristóteles entiende que Meliso cree poder admitir que si todo lo que es generado tiene un principio, entonces lo que no es generado no tiene principio; consecuencia: si el universo no es generado, será por tanto infinito. Pero Meliso, no ha caído en ninguno de estos errores, por el simple motivo que él no ha seguido el procedimiento lógico que dice Aristóteles. Su razonamiento gira a lo largo de un eje que escapa a la crítica aristotélica, y que es

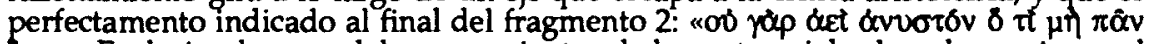
cotı». Es decir, el perno del razonamiento, el elemento axial sobre el que gira es el 
de hecho hubiese nacido, tendría un principio (pues en un cierto momento habría comenzado a nacer) y un fin (en un cierto momento habría terminado de nacer); pero, puesto que no ha comenzado ni terminado y era y será siempre, no tiene por tanto, principio ni fin. Pues, nọ es posible que sea siempre y no sea todo ${ }^{11}$

Este fragmento contiene indudablemente un punto clave de la doctrina de Meliso, pues se aleja paulatinamente del pensamiento de Parménides ${ }^{12}$. Parménides insistía de todos los modos posibles,

concepto de $\pi \hat{\alpha} v$, el concepto de "todo" o de "totalidad" que desaparece en la traducción del razonamiento de Meliso hecha por Aristóteles.

La interpretación de Burnett y Offner sostenia que Meliso en el fragmento 2 solamente hablaba del infinito temporal y nunca del infinito espacial. La hipótesis vendría confirmada por la utilización en el fragmento de la fórmula det y detorov. Sin embargo, los fragmentos que han sobrevivido parecen indicar que con el

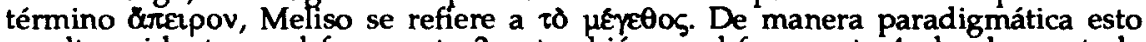
resulta evidente en el fragmento 3; y también en el fragmento 4, donde con toda

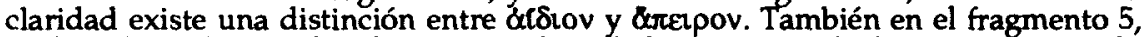
de la infinitud es deducida la unidad, se habla siempre de ourelpov en sentidó

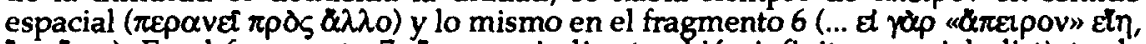

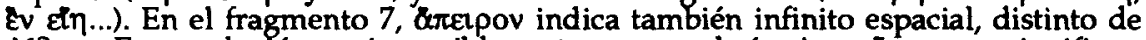
ódovov. En conclusión, es imposible sostener que el término «Qjelpov" signifique ilimitado temporalmente, sólo en el fragmento 2, frente a la significación precisa de

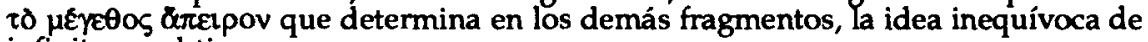
infinito en el tiempo.

11 SIMPLICIO, Phys., 162, 29: DK 30 B 2. La misma idea se observa en otros pasajes: "Pero, como siempre es, así también debe ser siempre infinito en grandeza" (DK 30 B 3). «Nada que tenga principio y fin es eterno ni infinito» (DK 30 B 4).

12 Recordemos el fr. 8 de Parménides :

«Pero inmóvil en los límites de las grandes ligaduras ( $\mu \varepsilon \gamma \alpha \lambda \omega v$ ev $\pi \varepsilon f \rho \alpha \sigma$

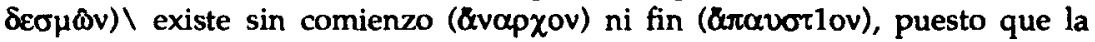
génesis y la destrucción \se pierden a lo lejos, apartados de la (fe) convicción verdadera.l $Y$ siendo lo mismo, en lo mismo permanece, descansa en sí mismo; \y así permanece firme en su posición, pues la poderosa necesidad

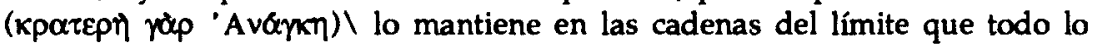

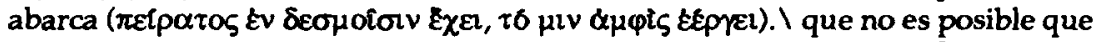

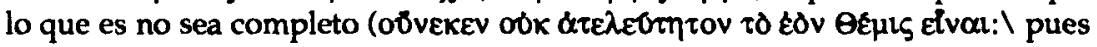
nada le falta y si no, le faltaría de todo. \" (26-28). Y sigue un poco más abajo «Pero puesto que hay un último límite, es completo y acabado por $\backslash$ doquier, semejante a la masa de una esfera bien redonda, $I$ absolutamente equidistante a partir del centro, pues no es posiblel ser mayor de un lado o menor 1del otro para nada: \pues lo que no es no puede impedirle alcanzar \la homogeneidad, 
en la determinación y en la delimitación de $s u$ "ser». La concepción de la perfección, que suele considerarse típicamente griega, excluye el infinito y obliga necesariamente a postular la finitud, la limitación y la determinación. Lo no completo y la infinitud son rigurosamente rechazados. Y para este propósito la idea de la «esfera» $(\sigma \varphi \alpha i p \alpha)^{13}$ genera de forma particular la idea de completo, de delimitación absoluta y determinación. Esta imagen es para algunos estudiosos de Parménides la demostración de la concepción materialista y fisicista que todavía tiene, para otros no debe de verse más que una metáfora o imagen, incluida no para designar la forma del ser, sino para indicar su homogeneidad, el equilibrio o su esencial intelegibilidad. Se puede entender esta imagen como expresión e ilustración del concepto de $\tau \varepsilon \tau \varepsilon \lambda \varepsilon \sigma \mu \varepsilon v o v$ $\pi \measuredangle v \tau o \theta \varepsilon v$, que inmediatamente le precede. Según Reale ${ }^{14}$, este término no puede entenderse ni como expresión demasiado

ni lo que es que de algún modo sea $\backslash$ aquí o allí mayor o menor ya que es por completo intacto: $\backslash$ pues, igual por todas partes a sí mismo, reina de una manera homogénea en los límites. I"

13 Parménides concebía al ser como esfera (fr.8, 43), contra tal concepción Meliso

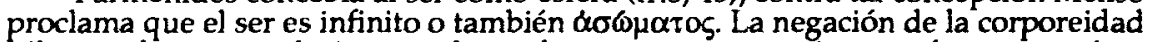
sólo puede querer decir que el ser, lo uno no posee ninguna forma corpórea determinada. El término «esfera» en Parménides es problemático (entre los antiguos físicos, ya desde Anaximandro, se piensa que la esfera arrastra la tierra junto con los demás cuerpos celestes, y de acuerdo con los pitagóricos organiza los intervalos de la escala musical), he expuesto en páginas precedentes que estamos ante una formulación en términos de representación intuitiva. $\mathrm{Si}$ se quisiera realizar una exégesis del concepto "esfera" tendríamos que preguntarnos si estamos ante una concepción dinámica o estática. Si fuera esfera estática encontrariamos algún problema, pues si el ser parmenídeo es indiferenciado lógicamente, como parece ser, entraria en conflicto con una idea de esfera pasiva o estática que está perfectamente limitada, hasta físicamente. Esta tensión sería resuelta por la hipótesis que propone Calogero (Calogero, G., Studi sull'eleatismo, Firenze, (n.e.), 1977, pp. 26 y ss.): la esfera sería dinámica, como infinitamente en progresión desde el centro hacia un límite por todas partes igual. En suma, Parménides no pensaría en la superficie esférica o en el sólido esférico, no se trata de una esfera, sino de un progresar continuo en forma de esfera. $\sigma \varphi \alpha f p \alpha, \alpha \varsigma$ (todos los cuerpos redondeados), particularmente nos podemos referir a un balón para jugar o a los astros, a las matemáticas o la geografía. La esfera como figura geométrica es utilizada por Parménides, por Platón en el Sofista, 244e etc.

14 Meliso, Testimonianze e frammenti, a cura de Giovanni Reale, Firenze, 1970, pp. 69-70. 
materialista, ni como expresión metafórica, sino como una formulación en términos de representación intuitiva (frecuente en el pensamiento arcaico) de aquella noción de perfección, determinación y finitud del ser.

Existe un pequeña contradicción, a nuestro parecer, en la caracterización de Parménides, que obliga a Meliso a resolverla. Se puede señalar un contraste suficiente entre la concepción del ser como lógica y absolutamente indiferenciado, esto es como absolutamente homogéneo y la afirmación de la finitud del mismo que no viene deducida ni es deducible de aquélla. Más rotundamente, la elección de la finitud del ser en Parménides es arbitraria y difícil de conciliar con su tesis de fondo. Si releemos los versos 26-32 del f. 8 parmenídeo, atendiendo al contraste entre la afirmación del verso 26 (en particular la expresión $\mu \varepsilon\}\{\lambda \omega \nu$ ह่v $\pi \varepsilon\{\rho \alpha \sigma i \delta \varepsilon \sigma \mu \hat{\omega} v)$ y los atributos que inmediatamente acompañan en el verso siguiente $\alpha v \alpha \rho \chi o v^{15}$ y $\alpha \pi \alpha v \sigma \tau o v^{16}$, a los cuales han seguido expresiones que reconocen los límites, que determinan y completan el ser: $\kappa \rho \alpha \tau \varepsilon \rho \eta \eta \gamma$

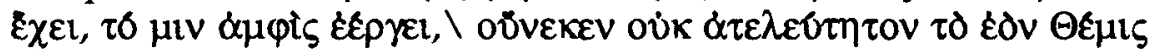
Elvol. Y si atendemos al contraste, todavía más evidente, entre la afirmación del verso 8,4 , que dice que el ser es $\alpha \tau \varepsilon \lambda \varepsilon \sigma \tau o v^{17}$ y la

15 (sin comienzo, sin principio): sobre el significado de este término ver

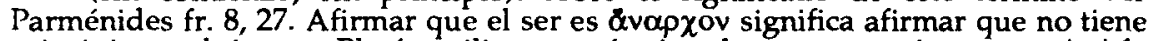
principio en el tiempo. Platón utiliza este término de manera pasiva como sin jefe, sin maestro en Leyes, 639 a. En otro sentido, lo utiliza Sexto Empírico como sin primeros principios; de manera activa, significaría que no tiene cualidades para mandar.

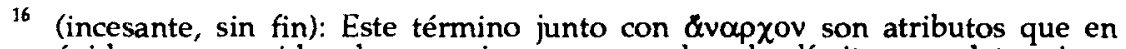
Parménides son seguidos de expresiones que recalcan los límites que determinan el ser.

17 (inacabado, sin fin): es un atributo que, según Reale (Cfr. REALE, G., Op. cit., pp. 45-59), Parménides refiere a su ser limitándolo sólo al tiempo. Parmenides parece que afirma la absoluta presencia del ser en el ahora vov, la atemporalidad del ser. Así, este concepto querría decir "sin fin $(\tau \varepsilon \lambda \circ \varsigma)$ temporal». A este atributo

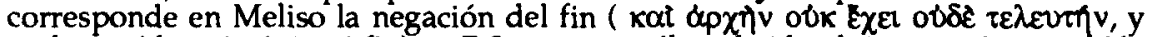
no ha tenido principio ni fin) en B 2, pero no sólo referido al tiempo, sino también al espacio. El término $\alpha \tau \varepsilon \lambda \varepsilon \sigma \tau o v$ ha puesto en serios aprietos a numerosos estudiosos. Alguno ha propuesto corregir el texto y leer $\eta \delta \varepsilon \varepsilon \varepsilon \lambda \varepsilon \sigma \tau \delta \sigma v$ (en lugar de $\left.\eta \delta^{\prime} \alpha \tau \dot{\ell} \lambda \varepsilon \sigma \tau o v\right)$. 
afirmación del verso 8,42, que lo dice $\tau \varepsilon \tau \varepsilon \lambda \varepsilon \sigma \mu \varepsilon v o v$. En fin, atendiendo a una consideración rigurosa, no es posible pensar y afirmar el ser como \&v $\alpha \rho \chi 0 v$ y $\alpha \tau \varepsilon \lambda \varepsilon \sigma \tau o v$ y pensar y afirmar el ser también como $\tau \varepsilon \tau \varepsilon \lambda \varepsilon \sigma \mu \varepsilon ́ v o v$.

La originalidad de Parménides en la elección del ser como elemento decisivo puede ser mostrada, igualmente, por una comparación temática con el único filósofo que puede servirle de precursor, Jenófanes ${ }^{18}$. Pierre Aubenque insiste en su artículo ya citado $^{19}$ en esta comparación más que interesante. En Jenófanes encontramos una teología de lo Uno, no una filosofía del ser. Aristóteles atribuye a Jenófanes la tesis de que lo «uno» es (lo)

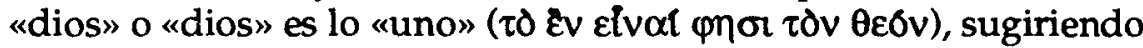
después que ese "dios" no es más que el nombre que Jenófanes dio al Universo $0^{20}$. Otras fuentes atribuyen a Jenófanes la deducción de algunos atributos de dios: 1 . eterno; 2 . uno; 3 . homogéneo en todas sus partes y determinado; 3 . esférico; 4 . dotado de sensación en todas sus partes ${ }^{21}$.

Es curioso que los cuatro primeros de esos predicados son los mismos que enumera Parménides en su largo desarrollo del fragmento VIII, $1-49^{22}$. Sí bien es cierto, que los predicados

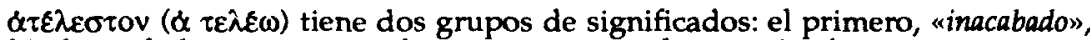
de dónde se deducen tres sentidos, "que no se concluye», "sin efecto, oano», "que no se termina, sin fin", el segundo sentido nos interesa menos, pues se refiere a "no estar iniciado en".

18 Aristóteles dice que fue su alumno, Metaf., A, 5, 986b 22.

19 Cfr. AUBENQUE, P., art. cit., pp. 105-106.

${ }^{20}$ Loc. cit., 23-25.

21 Cfr. DK 21 A 28 y 33.

22 Es curioso que las pequeñas contradicciones que vemos en la caracterización del ser de Parménides, tienen una correlación en Jenófanes también, como si la tradición quisiera buscar un paralelismo sugerente. Es más, observa Aubenque (art. cit., p. 106 que hasta una pequeña contradicción que la tradición concerniente a Jenófanes le aplica, tiene su paralelismo en Parménides: según Hipólito, el dios de Jenófanes es finito ( $\pi \varepsilon \pi \varepsilon \rho \alpha \sigma \mu \varepsilon \mu o v)$ (HIIPPOL., Ref., I, 14: DK 21 A 33), pero según Simplicio, que dice seguir en esto a Teofrasto, ese mismo dios no es ni finito ni

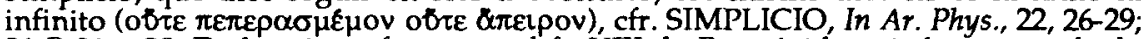
21 B 31 y 28. De la misma forma en el fr. VIII de Parménides, si el ser es acabado

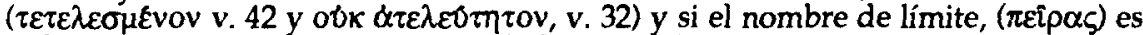
utilizado tres veces a este propósito $(v .31,42$ y 49)*, no es menos cierto que un poco 
enumerados por Parménides y Jenófanes son los mismos, existe una diferencia esencial y es que los sujetos que los reciben, no son los mismos. Mientras Jenófanes habla de dios, Parménides habla del ser, o más precisamente, de lo que es, to ḱov (aunque hay dificultades para encontrar claramente la forma sustantiva del verbo ser, -si hacemos abstracción del f. IV, cuyo lugar es discutido y la lectura controvertida de VIII, 12- más que a partir de VIII, 19). Estas significativas contradicciones, obligan a Meliso a recomponer el «ser» de Parménides en el uno, eterno, infinito y homogéneo, determinando un viraje que abre una fractura en la gnoseología eléata que tendrá consecuencias escépticas insospechadas.

II

Las razones que acabo de presentar son válidas para comprender la rectificación de algunos conceptos parmenídeos, pero no explican por qué su gnoseología es reconocida por los propios escépticos $^{23}$ como antecesora del escepticismo. La causa de esta

más arriba utiliza el nombre $\alpha \tau \varepsilon \lambda \varepsilon \sigma \tau o v$ que puede ser traducido por infinito (nosotros hemos traducido por bien acabado, -eterno, sin final, Liddell-Scott, p. 269). Se dirá que no es la misma cosa afirmar, como hace Parménides, o negar, como lo hace Jenófanes, dos atributos contrarios del mismo sujeto. No obstante, esto significaría que Parménides está prefigurando la segunda hipótesis del Parménides de Platón y fenófanes la primera, lo que significaria por la aparición definitiva en Platón, que ellos pertenecen a una misma tradición.

\footnotetext{
*Esta es la discusión de Aristóteles para quien lo Ũno de Parménides, siendo formal

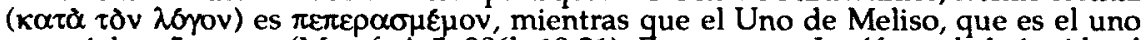
material es \& $\pi \varepsilon t \rho o v$ (Metaf. A 5, 986b 18-21). En cuanto a Jenófanes habría sido el primero en "confundir" las dos causas material y formal y no las distingue claramente, siendo imposible para él reconocer la naturaleza de la una y de la otra (986 b 21-23).

${ }^{23}$ En este sentido, Timón, el discípulo de Pirrón, elogia a Zenón y Meliso. De Zenón elogia el discurso dialéctico de Zenón es la base de su filosofía crítica, que le lleva a ser crítico de todos los demás filósofos. De Meliso, recoge su resistencia a valorar las apariencias erróneas del mundo sensible, dedicándole un magnífico homenaje al decirnos que se mostró superior a la mayor parte de las falsas opiniones, y que le influyeron bastante poco,: "El gran poder inagotable de Zenón, de discurso dialéctico, crítico de todos, y Meliso, por encima de muchas apariencias ( $\pi \circ \lambda \lambda \hat{\omega} v \varphi \alpha v \tau \alpha \sigma \mu \hat{\omega} v \dot{\varepsilon} \pi \alpha v \omega$ ), cediendo a pocas de ellas", D.L., IX, 25: DIELS, Poet., 9 B 45. El problema se manifiesta cuando la razón advierte que no tiene más remedio que apoyarse en los sentidos, al ser ellos los únicos cauces que tenemos para el conocimiento.
} 
importante variación viene determinada por la necesidad de fundamentar esa reconstrucción de los atributos del «ser» en una gnoseología radical: la crítica a cualquier tipo de conocimiento sensible. Si atendemos a los sentidos, medita Meliso, sólo percibimos cosas cambiantes, movimiento continuo en un mundo de apariencias que configura un mundo contradictorio y falaz donde predomina el tránsito del ser al no-ser. Sin embargo, esta consideración es inaceptable para Meliso, pues la realidad es una e indivisible, no generada y eterna, homogénea, inmóvil y no sujeta a nacimiento - cambio. Así, mientras Parménides afirma tanto la absoluta realidad del ser, como sus predicados a partir de la fundamental certeza lógica de que podemos decir "es" y no podemos decir "noes", Meliso, para quien la originaria ontologización del lógico Parménides no es un problema sino una premisa indiscutible y verdadera en su sentido metafísico, exige, ordenadamente, la inexistencia del vacío a partir del concepto de ser (ente) uno y homogéneo y su inmovilidad a partir de la inexistencia del vacío. Además, la existencia en Parménides de una exigencia ontológicolingüística se encontraba equilibrada con un incipiente logicismo; en Meliso, por contra, su situación especulativa conduce a la creación de una lógica muy ontologizada que excluye todo aquello que no sea algo intelectivo; es decir, todo aquello que provenga de la percepción sensible. Aquí radica la fractura que venimos advirtiendo y que no se reconoce como tal en Meliso, pues pensar única y exclusivamente dentro de los límites de la razón prepara el trayecto hacia el escepticismo. La afirmación, según la cual lo que no corresponde a las exigencias de la razón no puede ser real, deja a la propia razón sin fundamento, sin medida, ni límites; propiciando que la razón intente determinar lo que existe, internamente, sin ningún tipo de control.

La propuesta fundamental de Meliso establece, radicalmente, una separación tajante, no parmenídea, entre apariencia (sensible) y ser (inteligible): la pluralidad que percibimos del mundo sensible es apariencia errónea, mientras que el acto de aprehensión del ser por el pensamiento, invalida justamente ese devenir. La consecuencia 
epistemológica de este enunciado tiene necesariamente que admitir la eternidad, infinitud y homogeneidad del ser. Un texto del anónimo reconoce de manera sintética esta importante idea:

"De suerte que puesto que no puede ser así, no es tampoco posible que los seres sean múltiples, sino que lo parecen (no

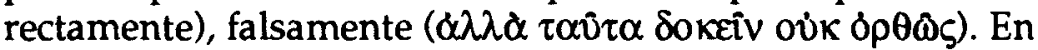
efecto, muchas otras cosas también se aparecen de forma

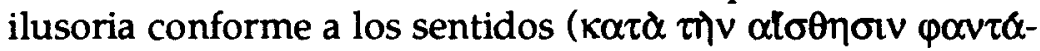
$\zeta \varepsilon \sigma \theta \propto 1)$; en cambio, el pensamiento invalida (no acepta) entonces que esas mismas cosas sucedan en el devenir, ni que el ser sea muchos, sino que sea uno, eterno, infinito y totalmente homogéneo consigo mismo"24.

Asistimos, pues, a un hábil ataque, desde la lógica melisiana, a la validez de los sentidos: consecuencia irrenunciable de su ruptura con la falsa realidad sensible. Advertimos con este argumento, el intento de rebatir la pluralidad mediante el método de reductio ad absurdum ${ }^{25}$, concluyendo de la siguiente forma: afirmar la existencia de una pluralidad engañosa sobre lo que aparece, sólo es posible si y solo si renunciamos a la unidad: lo cual es imposible. Por eso, hay que descartar que el ser sea producido por una mezcla ${ }^{26}$, ya sea generada por yuxtaposición o por superposición de la pluralidad en lo uno, ya que de aceptar la pluralidad excluiríamos absolutamente toda unidad.

Esta disyunción excluyente es radical en Meliso: si existe incompatibilidad entre unidad y multiplicidad, como parece que

\footnotetext{
24 DE M.J.G., 974 B, 3-8: DK 30 A 5.

${ }^{25}$ Cfr. ROMÁN, R., "Epicuro y Lucrecio: un intento antiescéptico de fundamentación del conocimiento", Almirez (U.N.E.D. Córdoba), 2, 1993, pp. 11-23, vid, p. 14. Véase la nota 12 de ese mismo artículo donde se recoge la afirmación de Kirk según la cual, esta actitud estableció la base de todo el sistema de los atomistas griegos, y el desacuerdo en este punto de Guthrie y Calogero.

${ }_{26}$ Cfr. M.J.G., 974 a-b: DK 30 A 5 . Esta cuestión presenta un problema, ya que existe una aparente unidad de las mezclas, por un lado, y por otro, también se presenta de manera manifiesta la pluralidad de los sujetos constituyentes de las mezclas, por lo que se podría decir que la mezcla es toda ella a la vez, todo ser y todo devenir. Pero, claro está, al adoptar la mezcla debería renunciarse a cualquier unidad del orden que sea. Veamos como se resuelve esta aparente contradicción.
} 
existe, habrá que renunciar a alguna de ellas: a la unidad no se puede renunciar pues lo uno sólo puede ser uno, eterno, homogéneo ${ }^{27}$; luego hay que renunciar a la pluralidad: "Pero es todo, y

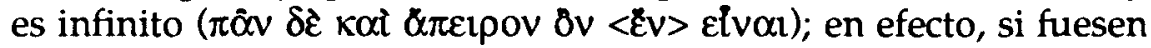
dos o más se limitarían los unos por los otros ${ }^{\prime 28}$. Si como la lógica demuestra la unidad es todo, $\pi \hat{\alpha} v^{29}$, entonces hay que renunciar a la pluralidad, puesto que la unidad no puede ser compatible con la pluralidad, ya que ella sola no puede ocupar a la vez el "ser" y el "aparecer", pues no es posible que el ser pueda ser muchos, y por tanto, tampoco es posible que los seres sean múltiples ya que esto presupondría el movimiento y el no-ser. A partir de aquí se puede hablar de una cierta ruptura con el pensamiento de Parménides: estas mismas hipótesis empujan a establecer explícitamente la oposición entre ser y aparecer. Lo uno es, la pluralidad aparece, no es más que apariencia errónea, falsa ${ }^{30}$. Si la pluralidad, por tanto, no es, tampoco puede ser que aparezca. Ese aparecer no es un aparecer de los fenómenos ( $\varphi \alpha$ tve $\sigma \theta \alpha \mathrm{l}$ ) en sentido estricto, como posteriormente reivindicarán algunos escépticos, sino un aparecer ( $\delta$ okeiv) erróneo donde hay ausencia de rectitud, de orden, es un puro imaginar, o también un puro

\footnotetext{
27 Estas características de lo uno: su homogeneidad, su falta de limitación, su imposibilidad de crecer o disminuir (ya que no puede cambiar) se completan con la ausencia de aflicciones el todo es sereno, sin sufrimientos ya que de experimentar padecimientos no sería uno, pues se convertiría en otro: "Por tanto es eterno, limitado, uno y homogéneo. Y no podría perecer ni hacerse mayor, ni cambiar de organización. Tampoco padece ni se aflige, ya que si sufriera alguna de esas afecciones, ya no sería uno". SIMPLICIO, Phys., 111, 18, 1: DK 30 B 7.

${ }^{28}$ De M.J.G., 974 a, 11-12: DK 30 A 5.

2 El concepto de $\pi \hat{o} v$ es fundamental en Meliso y se corresponde, según Reale, a lo que hoy denominariamos el absoluto (ver B 2, B 7). Hay una reciprocidad entre eternidad de la duración y totalidad espacial en Meliso. Es decir, lo que no es

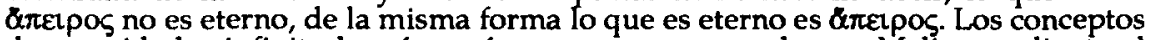
de eternidad e infinitud están recíprocamente conectados en Meliso mediante el concepto de totalidad $(\pi \hat{\alpha} v)$. Posiblemente, Meliso no acertó a representar este razonamiento con tanta claridad, pero es evidente, al menos eso parece, que esta es la línea de pensamiento desarrollada en el fragmento 2: of yớp oúl etvol

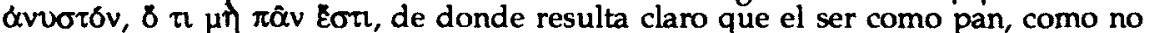
ha tenido límites en el tiempo, no ha tenido límites en el espacio: las dos series del tiempo y del espacio, pueden anularse en la totalidad del ser.

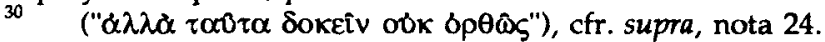


fantasear que es característico de la sensibilidad. Idea recogida convenientemente en un texto del anónimo: "En efecto, muchas otras cosas también se aparecen de forma ilusoria ( $\varphi \propto v \tau \alpha \zeta \varepsilon \sigma \theta \alpha a)$

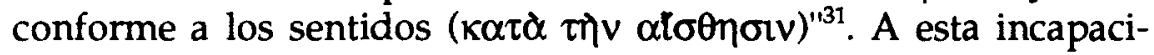

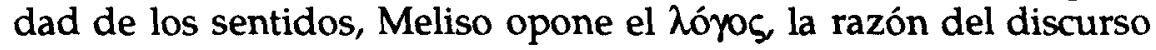
que es lo único que puede llevar a un conocimiento cierto de la realidad, del ser. La ineptitud de los sentidos no solo se manifiesta en aquellos casos en los que lo uno aparece erróneamente como múltiple, sino que muchas otras cosas u objetos son apariencias, imágenes o fantasmas.

Este razonamiento sobre la multiplicidad y la unidad configura en Meliso la distinción radical entre el mundo de la $\delta 6 \xi \alpha$ y el mundo de la $\alpha \lambda \eta \theta \varepsilon 1 \alpha$ : primero, convierte la dóxa y la alëtheia de Parménides en dos conceptos bien diferentes, y segundo, los hace portadores de una contradicción que imposibilita su coexistencia. Lo más importante del caso es que esa contradicción no aparece tan clara en el Poema de Parménides ${ }^{32}$. Meliso parece estar disolviendo el mundo de la dóxa parmenídea ${ }^{33}$; lo excluye rigurosamente del conocimiento; pues en su sistema no podían tener cabida de ninguna forma las opiniones que los mortales tienen sobre lo que aparece. Meliso plantea aquí una línea de derivación muy elaborada, ya que la negación de la pluralidad de los objetos y sus cualidades sensibles establece la imposibilidad de conocer la realidad por medio de los sentidos; ni vemos, ni oímos, ni conocemos lo que las cosas son: lo que no corresponde a la esfera de la razón no puede ser real, a pesar de ser testimoniado por los sentidos. Será, pues, la razón en su actividad la causante de la determinación de la realidad, mientras que la sensibilidad en su

\footnotetext{
${ }^{31}$ De M.J.G., 974 b 5-6: DK 30 A 5.

32 Cfr. Calvo, T., "Truth and Dóxa in Parmenides", Archio für Geschichte der Philosophie, 59, (1977), pp. 245-260, principalmente pp. 255-260 y Martinez Marzoa, F., Heráclito. Parménides (Bases para una lectura), Murcia, 1987, pp. 41-47.

${ }^{33}$ Esta buena consideración, importantísima para nuestro estudio, se la debemos a Reinhardt, cfr. REINHARDT, K., Parmenides, Frankfurt am Main, 1959, $4^{\mathrm{a}}$ ed. 1985, pp. 72-73, de esta misma opinión también es CALOGERO, G., Op. cit., pp. 72-73 y nota 3, el cual asume la observación de Reinhardt.
} 
pasividad conduce al error. La idea del hombre como observador que percibe será sacrificada por la idea del hombre que parece que constituye $u$ organiza la realidad sin atender a los datos de los senti$\operatorname{dos}^{34}$.

Esta radical distinción genera un problema de difícil desenlace. Si los sentidos son rechazados por ser testimonios erróneos, la pregunta inmediata sería ¿no estamos rechazando también indirectamente la razón que toma sus certezas de ellos mismos? La dificultad de esta cuestión radica en la imposibilidad de resolverla, terminando, como consecuencia, en el escepticismo resignado ${ }^{35}$. Si desconfiamos de los sentidos, tenemos que desconfiar de la razón y si la razón no puede sustentarse, y los sentidos tampoco, ¿qué nos queda? A lo mejor o peor, tal como proponen los escépticos suspender nuestro asentimiento. En resumen, la necesidad impuesta por el sistema de Meliso de que el conocimiento verdadero sólo se obtiene a través del logos, a través de la razón demostrativa ${ }^{36}$, será uno de los argumentos más frecuentemente utilizados por los escépticos para dudar del conocimiento en general. Ciertamente, este atisbo de escepticismo eleático (al menos en lo que a los sentidos se refiere) era filosóficamente estéril, ya que es de raíz metafísica y no epistemológica, pero inició la vía en la que más tarde se reconocerán, plenamente, los mismos

${ }^{34}$ Esta idea que destaca la primacía de la razón sobre la percepción en Meliso nos parece interesante, aunque no compartimos la ampliación que hace Zafiropulos a todo el pensamiento griego, Cfr. ZAFIROPULOS, J., L'école Étéate, Paris, 1950, pp. 247-248, mucho menos estamos de acuerdo con el paralelismo que construye este autor entre esta actitud griega y la de Kant en la Critica de la Razón Pura, que, según él, podía haber sido escrita por un griego del siglo $\mathrm{V}$ a. C.

${ }^{35}$ Esto es, sin duda, lo que supo Epicuro. De ahi que explícita y enérgicamente toda la gnoseología epicúrea descansa en la firme observación de que es por medio de la sensación como inferimos la existencia de los cuerpos. Para los epicúreos todas las sensaciones son verdaderas y no puede ninguna de ellas ser refutada por otra, ni tampoco por la razón que depende de ellas enteramente. De ahí, que la gnoseología epicureana sea un intento antiescéptico de fundamentar el conocimiento, cfr. supra, nota 25.

${ }_{36}$ Como ya hemos observado, en Meliso hay una rigurosa necesidad de excluir todos los valores propios de las dokoûnta, la verdad no puede provenir del examen de lo empírico, pues to múltiple es contradictorio, cfr. CALOCERO, G., Op. cit., p. 95, nota 16 y las páginas mencionadas de REINHARDT, K., Op. cit., pp. 71-73. 
escépticos antiguos. Así pues, por una extraña jugada del destino los filósofos más dogmáticos inician la linea de los más antidogmáticos. 